\title{
Incidence of hypothermia and analgesic use in the post- anesthesia care unit
}

\author{
Sami Eksert ${ }^{1}$, Ender Sır ${ }^{2}$ \\ (1) University of Health Sciences, Gulhane Training and Research Hospital, Department Anesthesia and Reanimation, \\ Ankara, Turkey \\ (2) University of Health Sciences, Gulhane Training and Research Hospital, Department of Algology and Pain \\ Medicine, Ankara, Turkey
}

Date submitted:

Apr 15, 2019

Date accepted:

May 09, 2019

Online publication date:

June 15, 2019

\section{Corresponding Author: \\ Sami Eksert \\ University of Health Sciences, \\ Gulhane Training and Research \\ Hospital, Department of \\ Anesthesia and Reanimation, \\ Ankara, Turkey \\ exert79@yahoo.com}

Keywords: Hypothermia, postoperative period, analgesics, anesthesia recovery period.

\begin{abstract}
Aims: Postoperative hypothermia $(\mathrm{POH})$ is a common but preventable adverse event. Our aim was to determine the incidence of $\mathrm{POH}$ and its effect on postoperative analgesic use in patients who underwent surgery in our hospital.
\end{abstract}

Methods: The files and anesthesia follow-up forms of 629 patients operated under general, neuraxial (spinal, epidural anesthesia), or regional anesthesia (peripheral nerve blocks) between March 2017 and May 2017 were reviewed retrospectively. Demographic data, anesthesia methods, surgical duration, post-anesthesia care unit recovery times, incidence of postoperative hypothermia, and postoperative analgesic use were evaluated.

Results: The incidence of $\mathrm{POH}$ was $22.1 \%$. $\mathrm{POH}$ occurred most often following thoracic surgery (26.3\%) and least often following urology operations (13.6\%), $(p=0.54)$. Regarding type of anesthesia, $\mathrm{POH}$ occurred most frequently with regional anesthesia (peripheral nerve blocks) (32.2\%), and least frequently with neuraxial anesthesia (spinal, epidural anesthesia), (14.9\%), $(p=0.01)$. However, the rate of analgesic use was lower in patients with $\mathrm{POH}$ in the postanesthesia care unit, although not statistically significant $(p=0.14)$.

Conclusion: $\mathrm{POH}$ is a frequently encountered problem in anesthesia practice, and the need for analgesia appears to be less in patients with $\mathrm{POH}$ in the post-anesthesia care unit.

\section{Introduction}

Intraoperative and postoperative hypothermia provokes thermal discomfort, decreases drug metabolism, and prolongs recovery (1). It also causes serious complications, such as surgical wound infections, stroke, coagulopathy, and myocardial complications (2). Additionally, hypothermia causes vasoconstriction and impairment of the immune system, which may increase the incidence of perioperative wound infection in patients (3). Basic guidelines indicate that patients should be normothermic in the perioperative period, therefore, patients must be heated during this time (4).

Human body temperature is controlled by the hypothalamus in a hormonal manner as a result of stimulation from thermo-receptors (5). Induction of anesthesia and cool environment of operating rooms have the potential to impair the physiological mechanisms of thermoregulation (6). Postoperatively, an internal body temperature below $36{ }^{\circ} \mathrm{C}$ is defined as postoperative hypothermia $(\mathrm{POH})(7)$. It has been shown that the incidence of $\mathrm{POH}$ is as high as $50-70 \%$ (8). The high rate of $\mathrm{POH}$ usually results from insufficient perioperative body temperature monitor- ing and the lack of necessary attention to $\mathrm{POH}$ in many centers (9). Although there are many safe and inexpensive procedures for maintaining patient temperature, perioperative hypothermia is still widely observed.

$\mathrm{POH}$ contributes to an increased need for transfusion, delay in wound healing, and delay in patient recovery and discharge, which may subsequently lead to losses in labor and finances $(2,3)$. Inadequate pain management also adversely affects the quality of life of patients during and after hospitalization. However, there are very few studies that have investigated the changes in analgesia requirements in patients with $\mathrm{POH}$, and no definite relationship between $\mathrm{POH}$ and postoperative pain has been established (10).

The aim of this study was to determine the incidence of $\mathrm{POH}$ and its effect on postoperative analgesic use in patients who underwent surgery in our hospital.

\section{Methods}

This study was planned as a retrospective study. After approval of the study by the hospital ethics committee (2018/5, 
18/105, date: 05.04.2018, Gülhane Training and Research Hospital), the files and anesthesia follow-up forms of patients who underwent surgery at our hospital between March 10, 2017 and May 10, 2017 were retrospectively reviewed. The study was conducted in accordance with the principles of the Declaration of Helsinki. The ethics committee waived the requirement for patient informed consent, because no patient re-contact was established for the study. Patients operated under general, neuraxial (spinal, epidural anesthesia), and regional (peripheral nerve blocks) anesthesia were included in the study. Intubated patients who were taken directly to the intensive care unit following surgery were excluded from the study. In addition, cases of cardiovascular and otorhinolaryngology surgery, which were not performed in the central operating rooms, were excluded from the study. Demographic data, the American Society of Anesthesiologists (ASA) physical status classification system scores, anesthesia methods, surgical duration, post-anesthesia care unit (PACU) recovery times, body temperature measured during admission to PACU, and analgesic drug information of the patients were obtained from the PACU follow-up forms. The patients were followed under standard monitoring (electrocardiography, noninvasive blood pressure, pulse oximeter) in PACU Opioids or non-steroidal anti-inflammatory drugs were administered to patients with a visual analog scale (VAS) score of four and above in PACU, postoperatively. Patients with score of eight and above were discharged from the PACU unit according to the Aldrete discharge score. Aldrete discharge score is the most frequent used scoring system to evaluate discharge readiness from PACU. Body temperature measurements were performed using an infrared tympanic thermometer after the surgical procedures, while the follow up of the patients in the PACU (Genius 2TM, Covidien LLC, Mansfield, USA). Hypothermia was defined as a body temperature below $36{ }^{\circ} \mathrm{C}$. Patients with hypothermia were heated with external and internal heaters in PACU. After the patients' tympanic temperatures were increased from $36.0^{\circ} \mathrm{C}$ and over, the patients were transferred to the clinic from PACU.

Statistical Analysis: After the data were transferred to a computer, analysis was performed using the Statistical Package for the Social Sciences (SPSS) 21.0 (SPSS Inc., Chicago, IL, USA). Data are presented as the number, percentage, mean, standard deviation, minimum, and maximum values. Mann-Whitney U-tests were used to compare continuous data from paired groups that were not normally distributed. A p value of $<0.05$ was considered to indicate statistical significance.

\section{Results}

The incidence of $\mathrm{POH}$ was $22.1 \%$ in the study. $\mathrm{POH}$ occurred most often following thoracic surgery $(26.3 \%)$ and least often following urology operations $(13.6 \%),(p=0.54)$. Regarding type of anesthesia, $\mathrm{POH}$ occurred most frequently with regional anesthesia (peripheral nerve blocks) $(32.2 \%)$, and least frequently with neuraxial anesthesia (spinal, epidural anesthesia), $(14.9 \%),(p=0.01)$. However, the rate of analgesic use was lower in patients with $\mathrm{POH}$ in the post-anesthesia care unit, although not statistically significant $(p=0.14)$.

Of the 652 patients whose files and follow-up forms were scanned, 23 were excluded due to missing data. A total of 629 patients were included in the study. The rate of $\mathrm{POH}$ was found to be $22.1 \%$. Demographic data, and operation times were similar, but PACU recovery times were significantly different between patients with and without $\mathrm{POH}$ (Table 1).

According to clinics, the highest $\mathrm{POH}$ rates were thoracic surgery $26.3 \%$, general surgery $25.9 \%$ and neurosurgery clinic

Table 1. Sociodemographic Data

\begin{tabular}{lccc}
\hline & $\begin{array}{c}\text { Hypothermia } \\
\text { (N:139) } \\
\text { Mean } \pm \text { SD }\end{array}$ & $\begin{array}{c}\text { Normo-hyperthermia } \\
\text { (N: 490) Mean } \pm \text { SD }\end{array}$ & \\
$\mathbf{p}$ & & & \\
Sex & & & \\
$\quad$ Male & $84(23.9)$ & $268(76.1)$ & 0.24 \\
$\quad$ Female & $55(19.9)$ & $41.32 \pm 20.02$ & 0.09 \\
\hline Age (Years) & $38.14 \pm 17.18$ & $35.46 \pm 11.86$ & 0.02 \\
\hline PACU Recovery Time (Min) & $39.36 \pm 18.61$ & $96.14 \pm 67.27$ & 0.84 \\
\hline Operation Time (Min) & $94.83 \pm 76.58$ & & \\
\hline
\end{tabular}

Table 2. Hypothermia Rates by Clinic

\begin{tabular}{lcc|}
\hline Clinic & $\begin{array}{c}\text { Hypothermia } \\
\mathbf{n}(\%)\end{array}$ & $\begin{array}{c}\text { Normo-hyperthermia } \\
\mathbf{n}(\%)\end{array}$ \\
\hline Neurosurgery & $7(25.9)$ & $20(74.1)$ \\
\hline Pediatric Surgery & $8(17.8)$ & $37(82.2)$ \\
\hline General Surgery & $44(25.1)$ & $131(74.9)$ \\
\hline Thoracic Surgery & $5(26.3)$ & $14(73.7)$ \\
\hline Ophthalmic Surgery & $5(17.9)$ & $23(82.1)$ \\
\hline Obstetrics And Gynecology & $22(22.4)$ & $76(77.6)$ \\
\hline Orthopedics & $29(25.9)$ & $83(74.1)$ \\
\hline Plastic Surgery & $8(18.2)$ & $36(81.8)$ \\
\hline Urology & $11(13.6)$ & $70(86.4)$ \\
\hline Total & $\mathbf{1 3 9 ( 2 2 . 1 )}$ & $\mathbf{4 9 0 ( 7 7 . 9 )}$ \\
\hline
\end{tabular}


Table 3. Hypothermia Rates by Anesthesia Method

\begin{tabular}{lcc|c|}
\hline & $\begin{array}{c}\text { Hypothermia } \\
\mathbf{n}(\%)\end{array}$ & $\begin{array}{c}\text { Normo-hyperthermia } \\
\mathbf{n}(\%)\end{array}$ & $317(77.7)$ \\
\hline General & $91(22.3)$ & $114(85.1)$ \\
\hline Neuraxial (Spinal, Epidural Anesthesia) & $20(14.9)$ & $59(67.8)$ \\
\hline Regional (Peripheral Nerve Blocks) & $28(32.2)$ & $490(77.9)$ \\
\hline Total & $139(22.1)$ & 491 \\
\hline
\end{tabular}

Table 4. Analgesic Use in Patients With and Without POH

\begin{tabular}{|c|c|c|c|}
\hline & $\begin{array}{l}\text { Hypothermia } \\
\text { n (\%) }\end{array}$ & $\begin{array}{c}\text { Normo-hyperthermia } \\
\text { n (\%) }\end{array}$ & $\mathbf{p}$ \\
\hline No Postoperative Analgesic Use & $125(89.9)$ & $428(87.3)$ & \multirow{2}{*}{0.14} \\
\hline Postoperative Analgesic Use & $14(10,1)$ & $62(12.7)$ & \\
\hline Total & $139(22.1)$ & $490(77.9)$ & \\
\hline
\end{tabular}

25.9\%. The lowest POH ratio was urology with $13.6 \%$. There was no statistically significant difference between the $\mathrm{POH}$ rates according to the clinic $(\mathrm{P}=0.54)$ (Table 2).

According to anesthesia methods, $\mathrm{POH}$ rates were regional anesthesia $26.3 \%$, general anesthesia $22.3 \%$ and neuraxial anesthesia $14.9 \%$. There was a statistically significant relationship between the $\mathrm{POH}$ rate and anesthesia method $(P=0.01)$, (Table 3).

Analgesic using rate was $10.1 \%$ in patients with $\mathrm{POH}$ and $12.7 \%$ with normo-hyperthermia. Although statistically insignificant, there was a lower rate of analgesic use in patients with $\mathrm{POH}(\mathrm{P}=0.14)$, (Table 4).

\section{Discussion}

In this study, we aimed to determine the incidence of $\mathrm{POH}$ and its effect on postoperative analgesic use in patients who underwent surgery. We observed that the incidence of $\mathrm{POH}$ was $22.1 \%$. POH occurred most often following chest surgery and least often following urology operations. Regarding type of anesthesia, $\mathrm{POH}$ occurred most frequently with regional anesthesia, and least frequently with neuraxial anesthesia. Further, the rate of analgesic use was lower in patients with $\mathrm{POH}$, although not statistically significant.

Although the incidence of $\mathrm{POH}$ is in the range of $50-70 \%$ in literature, we found an incidence of $22.1 \%$ in our study (8). According to a survey conducted by Torossian et al. (11) in 801 representative hospitals from 17 European countries, the incidence of $\mathrm{POH}$ was observed to be high during the perioperative period owing to the lack of body temperature monitoring and active heating systems. In our clinic, per the American Society of Anesthesiologists (ASA) protocol, all patients undergoing surgery underwent thermal monitoring during the perioperative period (12). In addition, electric heaters were used at the operating tables during surgery, serum and blood products were heated while infusing, and patients were treated with active heating systems in the PACU following surgery. As a result, the incidence of $\mathrm{POH}$ was much lower in our study than in the literature (8).

The prevention of perioperative hypothermia is important in Enhanced Recovery After Surgery (ERAS) protocols (13). The recovery and discharge times of patients with $\mathrm{POH}$ are known to be prolonged $(3,4)$. In our study, in accordance with the literature, we found significantly longer recovery times in patients with $\mathrm{POH}$ than in those without. The implication is that $\mathrm{POH}$ extended the stay of patients in PACU and increased the workload of PACU staff.

There was no significant difference in the $\mathrm{POH}$ rate according to the clinic. However, $\mathrm{POH}$ was observed least commonly in patients who underwent surgery in the departments of urology, pediatrics, and ophthalmology, and most commonly in the thoracic surgery, orthopedic, and brain surgery clinics. This may be due to patient age and the width of the surgical site, as suggested in an earlier study (14). This indicates the need for more careful monitoring and close follow-up in these surgeries.

It is known that general, regional, and neuraxial anesthesia can disrupt heat thermoregulation and cause $\mathrm{POH}(11,15)$. In our study, $\mathrm{POH}$ was found to be low in patients undergoing neuraxial anesthesia (14.9\%), which is in accordance with the literature (16). In contrast, $\mathrm{POH}$ was more common in patients undergoing regional anesthesia (32.2\%). We believe that this was due to the fact that body temperature monitoring was not taken into account during the time period in which regional blockade was conducted. Additionally, the provision of adequate sensory block for surgery and preventive measures were not taken into account for the prevention of heat loss. Patients were not heated during this time, and warming was started after the patient's arrival to the operation room. As a result, the incidence of $\mathrm{POH}$ was higher in patients with regional blockade.

Su et al. (17) showed increased tremor, energy consumption, and postoperative surgical incision pain levels in patients with $\mathrm{POH}$. In a study by Benson et al. (14) pain intensity and opioid use were more common in patients with $\mathrm{POH}$. However, in the study by Persson et al. (10) there was no relationship between $\mathrm{POH}$ and analgesic use. Conversely, we found a lower rate of analgesic use in patients with $\mathrm{POH}$. Changes in neuronal physiology occur with a decrease in basal metabolism consumption and electrical activity in patients with hypothermia. This neuronal activity can produce nociceptive neuromodulation by reducing the transmission between the brain and spinal cord (18). Additionally, in one study, morphine clearance was significantly decreased in infants with hypothermia and elevated concentrations in blood were observed (19). Thus, the patients' need for analgesia is less in the PACU, as excretion of intra-operative analgesics is delayed and the blood levels of analgesics have not yet reduced. The implication is that $\mathrm{POH}$ causes a lower rate of pain in patients and decreases analgesic requirement in the PACU. 
In this study, we evaluated the use of analgesics in PACU and observed that patients with $\mathrm{POH}$ had less analgesic needs. However, in order to determine whether this is good or bad, patients with $\mathrm{POH}$ should be followed up longer in the postoperative period and analgesic use should be evaluated particularly when they become normothermia.

This study had several limitations, including its retrospective design, lack of randomization, and lack of homogeneity of patients in terms of surgical and anesthetic techniques. The follow-up period of patients was limited to the PACU, and hence, comprehensive information about postoperative pain could not be obtained. In addition, some factors that may affect postoperative pain such as type of surgery and associated pain, hospital protocols, age and drug availability were not evaluated. Therefore, the relationship between $\mathrm{POH}$ and postoperative analgesic use may not be fully elucidated.

\section{Conclusions}

In light of the findings obtained from the study, in order to decrease the incidence of $\mathrm{POH}$, patients who undergo surgery should also undergo standard body temperature monitoring, and preventive measures for maintaining perioperative body temperature should be taken. Monitoring will not reduce the incidence but it will alert the practitioner of the occurrence and thereby allow appropriate intervention. Patient and serum heating systems should be used, and protocols should be established to prevent $\mathrm{POH}$. Since the need for analgesia is less in patients with $\mathrm{POH}$, dose adjustments should be performed to prevent excessive accumulation and overdose. Additionally, in order to understand the relationship between $\mathrm{POH}$ and postoperative pain, prospective, randomized trials with standard analgesia protocols are needed in patients undergoing the same type of surgery and anesthesia.

Acknowledgements: The authors would like to thank $\mathrm{Dr}$ Soykan Sahin for help with the statistical analysis and Editage by Cactus for the proof reading of the manuscript.

Author contributions: Study was designed by SE and ES. Data was collected and analyzed by SE. Manuscript was written by SE and ES. Literature research was made by SE. Final approval of the manuscript: SE, ES. There was no financial assistance with the project.

Conflict of Interest: The authors declared that they do not have anything to disclose regarding conflict of interest with respect to this manuscript.

\section{References}

1. Leslie K, Sessler DI, Bjorksten AR, Moayeri A. Mild hypothermia alters propofol pharmacokinetics and increases the duration of action of atracurium. Anesth Analg. 1995; 80:1007-1014.

2. Rajagopalan S, Mascha E, Na J, Sessler DI. The effects of mild perioperative hypothermia on blood loss and transfusion requirement. Anesthesiology. 2008; 108(1):71-77.

3. Kurz A, Sessler DI, Lenhardt R. Perioperative normothermia to reduce the incidence of surgical-wound infection and shorten hospitalization. Study of Wound Infection and Temperature Group. N Engl J Med. 1996; 9;334(19):1209-1215.

4. Sun Z, Honar H, Sessler DI, et al. Intraoperative core temperature patterns, transfusion requirement, and hospital duration in patients warmed with forced air. Anesthesiology. 2015; 122(2):276-285.

5. Sessler DI. Temperature monitoring and perioperative thermoregulation. Anesthesiology. 2008; 109(2):318338.

6. Sessler DI. Complications and treatment of mild hypothermia. Anesthesiology. 2001; 95(2):531-543.

7. Sessler DI. Mild perioperative hypothermia. N Engl J Med 1997; 12;336(24):1730-1737.

8. Roberson MC, Dieckmann LS, Rodriguez RE, Austin PN. A review of the evidence for active preoperative warming of adults undergoing general anesthesia. AANA J. 2013; 81(5):351-356.

9. Ruetzler K, Kurz A. Consequences of perioperative hypothermia. Handb Clin Neurol. 2018; 157:687-697.

10. Persson K, Lundberg J. Perioperative hypothermia and postoperative opioid requirements. Eur J Anaesthesiol. 2001; 18(10):679-686.

11. Torossian A; TEMMP (Thermoregulation in Europe Monitoring and Managing Patient Temperature) Study Group. Survey on intraoperative temperature management in Europe. Eur J Anaesthesiol 2007; 24(8):668-675.

12. American Society of Anesthesiologists. Standards and Guidelines. https://www.asahq.org/standards-and-guidelines. Accessed April 15, 2019.

13. Horosz B, Nawrocka K, Malec-Milewska M. Anaesthetic perioperative management according to the ERAS protocol. Anaesthesiol Intensive Ther. 2016; 48(1):49-54.

14. Benson EE, McMillan DE, Ong B. The effects of active warming on patient temperature and pain after total knee arthroplasty. Am J Nurs. 2012; 112(5):26-33.

15. Glosten B, Hynson J, Sessler DI, McGuire J. Preanesthetic skin-surface warming reduces redistribution hypothermia caused by epidural block. Anesth Analg. 1993; 77(3):488-493.

16. Aksu C, Kuş A, Gürkan Y, Solak M, Toker K. Kocaeli Üniversitesi ameliyathanesi postoperatif hipotermi insidansı araştırması. Turk J Anaesth Reanim. 2014; 42(2):66-70.

17. Su SF, Nieh HC. Efficacy of forced-air warming for preventing perioperative hypothermia and related complications in patients undergoing laparoscopic surgery: A randomized controlled trial. Int $\mathrm{J}$ Nurs Pract. 2018; 24(5):e12660.

18. Giménez-Milà $M$, Videla $S$, Jenkins $D$, et al. Acute pain and analgesic requirements after pulmonary endarterectomy with deep hypothermic circulatory arrest. J Cardiothorac Vasc Anesth 2016; 30(4):993-996.

19. Róka A, Melinda KT, Vásárhelyi B, Machay T, Azzopardi D, Szabó M. Elevated morphine concentrations in neonates treated with morphine and prolonged hypothermia for hypoxic ischemic encephalopathy. Pediatrics 2008; 121(4):e844-849. 